\title{
Conceptual Model to Assess Factors Affecting Productivity of University Staff; An Exploratory Factor Analysis Approach \\ Research Article
}

Hamed Taherdoost ${ }^{*}$, Mitra Madanchian ${ }^{2}$, Mona Ebrahimi $^{2}$

${ }^{1}$ University Canada West, Vancouver, Canada.

${ }^{2}$ Research Club (Research \& Development Departement), Hamta Group | Hamta Business Corporation, Vancouver, Canada.

Abstract

Productivity of university members has been defined in different forms; however, no specific definition is presented to evaluate factors that determine the productivity of university members. This study intends to provide a certain definition for the productivity of university members including five major constructs that impact productivity and employs an Exploratory Factor Analysis Approach to propose a conceptual model for evaluation of the impact of these factors on the productivity of the staff in university.

\section{Introduction}

A range of different definitions has been provided to describe the productivity of university members. However, no certain standards and measures are stated to evaluate the productivity of university members. In this study, productivity is defined as the cost per learning unit for each student [1]. Productivity is mainly considered as positive if the education cost is less than the quality of student learning.

To evaluate the productivity of university members and design the research model, five main factors are introduced in this study to be measured including Organizational Behaviour, Environmental Conditions, Motivational Factors, Academic Qualification and Leadership Methods. These measures will be evaluated using the Exploratory Factor Analysis Approach that is a complex multivariate statistical method involving many linear and sequential steps to realize the structure of large sets of variables. A five-step guide is suggested to implement the Exploratory Factor Analysis in a case university.

In this paper, a specific definition for the productivity of university staff and its main constructs will be discussed, a conceptual model will be provided in the next section, and the Exploratory Factor Analysis will be employed in five major steps to investigate the responses received from questionnaires in a case university in the last section.

\section{Methodology - Exploratory Factor Analysis (EFA)}

This is a widely used statistical approach that is commonly applied in researches in psychology, education, social science, and information system topics. Exploratory Factor Analysis (EFA), and Confirmatory Factor Analysis (CFA) are two main classifications of factor analysis [2]. Exploratory Factor Analysis (EFA) is the best choice when there is not any understanding of the nature of the number of factors [3].

Exploratory Factor Analysis (EFA) is a sequential and linear approach that aims to reduce the number of variables, evaluate construct validity in a survey, assess multicollinearity among correlated factors, examine the structure of variables, assess the functionality of proposed theories, and develop theoretical constructs. Five steps have been employed in this study to utilize EFA including, Evaluation of Data Suitability for EFA, Factor Extraction Method, Factor Retention Method, Selection of Rotational Method, Interpretation, and Labeling [4]. Also, to evaluate the research model, a questionnaire has been designed that consists of 21 items to measure the predefined factors [5]. To measure each item the five Likert scales from 1 strongly agreeing to 5, being strongly disagree was utilized. Then, the questionnaire was distributed among 155 academic staff and after data filtering, 146 responses remained for further analysis $[6,7]$.

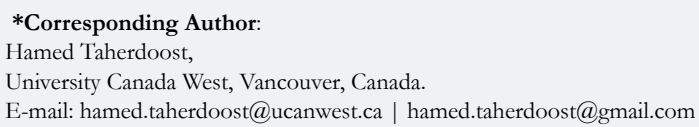

Citation: Hamed Taherdoost, Mitra Madanchian, Mona Ebrahimi. Conceptual Model to Assess Factors Affecting Productivity of University Staff; An Exploratory Factor Analysis Approach. Int J Financ Econ Trade. 2021;4(5):108-112. doi: http://dx.doi.org/10.19070/2643-038X-2100014

Copyright: Hamed Taherdoost 2021 . This is an open-access article distributed under the terms of the Creative Commons Attribution License, which permits unrestricted use, distribution and reproduction in any medium, provided the original author and source are credited. 


\section{Background and Analysis}

In this paper, the factors affecting on productivity of university members are evaluated using exploratory factor analysis. However, there is no specific definition for university productivity [8], it is indicated [9] that there is a lack of suitable and standard indicators to measure the university members' productivity. For this study, productivity is defined as the cost per learning unit for each student [1]. In fact, the productivity is considered as positive if the education cost is less than quality of student learning.

Organizational Culture which is the values or shared perceptions kept by faculty [10], known as one of the factors affecting productivity. Another construct influencing the productivity is environmental conditions. A good environment can increase personal ability and productivity and develop personal values. Empowerment which is defined as the process of increasing intrinsic motivation is the psychological concept related to the university members' beliefs and emotions about their job and organization. On the other hand, according to [11], it refers to power and decision sharing in an organization. Empowerment is one of the major factors to improve productivity [12]. Another component which may have effect on productivity of university members is motivational factors. Motives will lead to starting and continuing activities. Management Method is one of the principal tasks of manager and the process of effecting and directing the activities related to the members job. Loke [13] stated that Management is one of the significant factors influencing on efficiency, productivity and effectiveness. Sulo, Kendagor [14] introduced academic qualifications and funding as two other factors effecting on academic staff productivity.
In order to evaluate the research model, a questionnaire has been designed consists of 21 items to measure the seven introduced factors [15]. To measure each item the five Likert scale from 1 being strongly agree to 5 , being strongly disagree was utilized. Then the questionnaire was distributed among 155 academic staff and after data filtering, 146 responses were remained for further analysis [5].

Cronbach's alpha method was used for reliability testing. As it is shown in Table 1, the Cronbachûs Alpha with the range between 0.865 to 0.884 which prove that constructs are deemed to have adequate reliability [16-20].

In next step, the KMO (Kaiser-Meyer-Olkin) index is a measure of sampling adequacy, and the sphericity statistic tests. Table 2 indicates that the degree of common variance among the variables is quite high $[21,22]$.

Since [23] mentioned that principal components analysis (PCA) is useful if researcher has initially developed an instrument with several items and is interested in reducing the number of item, then for this study this method was used as factor extraction method.

After extraction phase and in order to decide how many constructs to retain for rotation, the K1 - Kaiser's [24] method was applied because this approach is the best known and most used in practice [25] because of its theoretical basis and ease of use [26]. As it is indicated in Table 3, five factors should remain for further analysis.

Table 1. Cronbach's alpha Results for the Survey.

\begin{tabular}{|c|c|c|}
\hline ITEM & $\begin{array}{c}\text { Scale Mean if } \\
\text { Item Deleted }\end{array}$ & $\begin{array}{c}\text { Cronbach's Alpha if } \\
\text { Item Deleted }\end{array}$ \\
\hline CUL 1 & 78.507 & 0.872 \\
\hline CUL 2 & 78.664 & 0.874 \\
\hline CUL 3 & 79.329 & 0.884 \\
\hline EMP 1 & 78.589 & 0.876 \\
\hline EMP 2 & 78.260 & 0.874 \\
\hline MOT 1 & 78.343 & 0.871 \\
\hline MOT 2 & 78.171 & 0.865 \\
\hline MOT 3 & 78.185 & 0.867 \\
\hline ENV 1 & 78.637 & 0.871 \\
\hline ENV 2 & 78.706 & 0.868 \\
\hline ENV 3 & 78.575 & 0.866 \\
\hline ACQ1 & 78.575 & 0.865 \\
\hline ACQ 2 & 79.027 & 0.872 \\
\hline ACQ 3 & 78.856 & 0.873 \\
\hline ACQ 4 & 78.911 & 0.875 \\
\hline MAN 1 & 78.411 & 0.868 \\
\hline MAN 2 & 78.034 & 0.869 \\
\hline MAN 3 & 78.069 & 0.868 \\
\hline FUN 1 & 77.980 & 0.869 \\
\hline FUN 2 & 77.986 & 0.869 \\
\hline FUN 3 & 78.404 & 0.872 \\
\hline
\end{tabular}


Table 2. KMO and Bartlett's Test.

\begin{tabular}{|c|c|c|}
\hline \multicolumn{2}{|c|}{ Kaiser-Meyer-Olkin Measure of Sampling Adequacy. } & $\mathbf{0 . 8 1 5}$ \\
\hline \multirow{2}{*}{$\begin{array}{c}\text { Bartlett's Test of } \\
\text { Sphericity }\end{array}$} & Approx. Chi-Square & 1793.876 \\
\cline { 2 - 3 } & df & 210 \\
\cline { 2 - 3 } & Sig. & .000 \\
\hline
\end{tabular}

Table 3. Total Variance Explained.

\begin{tabular}{|c|c|c|c|c|c|c|c|c|c|}
\hline \multirow{2}{*}{$\begin{array}{c}\text { Com- } \\
\text { ponent }\end{array}$} & \multicolumn{3}{|c|}{ Initial Eigenvalues } & \multicolumn{3}{|c|}{$\begin{array}{l}\text { Extraction Sums of Squared } \\
\text { Loadings }\end{array}$} & \multicolumn{3}{|c|}{$\begin{array}{c}\text { Rotation Sums of Squared } \\
\text { Loadings }\end{array}$} \\
\hline & Total & $\begin{array}{c}\% \text { of } \\
\text { Variance }\end{array}$ & $\begin{array}{l}\text { Cumula- } \\
\text { tive } \%\end{array}$ & Total & $\begin{array}{c}\% \text { of } \\
\text { Variance }\end{array}$ & $\begin{array}{c}\text { Cumula- } \\
\text { tive } \%\end{array}$ & Total & $\begin{array}{c}\% \text { of } \\
\text { Variance }\end{array}$ & $\begin{array}{c}\text { Cumula- } \\
\text { tive } \%\end{array}$ \\
\hline 1 & 6.931 & 33.003 & 33.003 & 6.931 & 33.003 & 33.003 & 4.077 & 19.416 & 19.416 \\
\hline 2 & 2.317 & 11.033 & 44.036 & 2.317 & 11.033 & 44.036 & 2.922 & 13.915 & 33.331 \\
\hline 3 & 1.957 & 9.318 & 53.355 & 1.957 & 9.318 & 53.355 & 2.811 & 13.385 & 46.715 \\
\hline 4 & 1.676 & 7.98 & 61.334 & 1.676 & 7.98 & 61.334 & 2.214 & 10.543 & 57.258 \\
\hline 5 & 1.24 & 5.907 & 67.241 & 1.24 & 5.907 & 67.241 & 2.096 & 9.983 & 67.241 \\
\hline 6 & 0.968 & 4.607 & 71.849 & & & & & & \\
\hline 7 & 0.916 & 4.36 & 76.208 & & & & & & \\
\hline 8 & 0.765 & 3.642 & 79.85 & & & & & & \\
\hline 9 & 0.629 & 2.993 & 82.844 & & & & & & \\
\hline$\smile^{-10}$ & 0.559 & 2.663 & 85.506 & & & & & & \\
\hline 11 & 0.528 & 2.514 & 88.021 & & & & & & \\
\hline 12 & 0.471 & 2.241 & 90.262 & & & & & & \\
\hline 13 & 0.433 & 2.062 & 92.324 & & & & & & \\
\hline 14 & 0.344 & 1.638 & 93.962 & & & & & & \\
\hline 15 & 0.29 & 1.381 & 95.343 & & & & & & \\
\hline 16 & 0.265 & 1.264 & 96.607 & & & & & & \\
\hline 17 & 0.184 & 0.875 & 97.481 & & & & & & \\
\hline 18 & 0.177 & 0.842 & 98.323 & & & & & & \\
\hline 19 & 0.152 & 0.722 & 99.045 & & & & & & \\
\hline 20 & 0.122 & 0.581 & 99.626 & & & & & & \\
\hline 21 & 0.079 & 0.374 & 100 & & & & & & \\
\hline
\end{tabular}

In order to decide if variables might relate to more than one factor, rotational approach was applied. Since the factors are not correlated, therefore, Varimax rotation was used [4, 27]. The results are shown in Table 4.

\section{Conceptual Model}

According to the results, only one of the items which is the item 3 of organizational culture should be deleted since the loading factor is below 0.5 and none of the items load over 0.5 on two factors.

Furthermore, one of the Funding items loads on Motivational Factor which can be deleted for further analysis although since it makes sense to be included in Motivational Factor, it also can be considered as Motivational Factor item. The final step, the five factors need to be labelled based on theoretical, subjective, and inductive process. Therefore, factors are labeled as Organizational Behavior, Environmental Conditions, Motivational Factors, Aca- demic Qualification and Leadership Methods.

Therefore, the conceptual model can be proposed as shown in Figure 1.

\section{Conclusions}

Five aspects of university staff productivity were evaluated through a five-step Exploratory Factor Analysis Approach and implemented in a case university to investigate their impact on productivity. Therefore, fundamental information about EFA with a stepwise and user-friendly guideline was provided to demonstrate the impact of Organizational Behaviour, Environmental Conditions, Motivational Factors, Academic Qualification, and Leadership Methods on the productivity of university members.

The five-step guide for implementation of exploratory factor analysis includes (1) evaluation of sample size adequacy using correlation matrix, Kaiser-Meyer-Olkin (KMO) and Bartlett's Test 
Table 4. Rotated Component Matrix.

\begin{tabular}{|c|c|c|c|c|c|}
\hline & \multicolumn{5}{|c|}{ Component } \\
\cline { 2 - 6 } & $\mathbf{1}$ & $\mathbf{2}$ & $\mathbf{3}$ & $\mathbf{4}$ & $\mathbf{5}$ \\
\hline CUL 1 & 0.117 & 0.157 & 0.115 & 0.306 & 0.576 \\
\hline CUL 2 & 0.049 & 0.27 & -0.145 & 0.316 & 0.565 \\
\hline CUL 3 & -0.331 & 0.088 & 0.208 & 0.343 & 0.208 \\
\hline EMP 1 & 0.157 & 0.049 & 0.013 & 0.007 & 0.785 \\
\hline EMP 2 & 0.167 & -0.026 & 0.286 & -0.037 & 0.701 \\
\hline MOT 1 & 0.106 & 0.183 & 0.812 & 0.051 & 0.082 \\
\hline MOT 2 & 0.487 & 0.13 & 0.694 & 0.184 & 0.102 \\
\hline MOT 3 & 0.462 & 0.145 & 0.683 & 0.183 & 0.055 \\
\hline ENV 1 & 0.044 & 0.854 & 0.193 & 0.014 & 0.097 \\
\hline ENV 2 & 0.11 & 0.908 & 0.165 & 0.07 & 0.085 \\
\hline ENV 3 & 0.157 & 0.805 & 0.216 & 0.134 & 0.203 \\
\hline ACQ1 & 0.403 & 0.474 & 0.08 & 0.558 & -0.082 \\
\hline ACQ 2 & 0.214 & 0.43 & -0.04 & 0.649 & -0.108 \\
\hline ACQ 3 & 0.335 & -0.128 & 0.091 & 0.677 & 0.135 \\
\hline ACQ 4 & -0.008 & 0.031 & 0.075 & 0.693 & 0.242 \\
\hline MAN 1 & 0.678 & 0.204 & -0.018 & 0.32 & 0.129 \\
\hline MAN 2 & 0.785 & 0.051 & 0.23 & 0.136 & 0.068 \\
\hline MAN 3 & 0.864 & 0.174 & 0.088 & 0.114 & 0.137 \\
\hline FUN 1 & 0.849 & 0.063 & 0.219 & 0.056 & 0.14 \\
\hline FUN 2 & 0.727 & 0.059 & 0.311 & -0.011 & 0.239 \\
\hline FUN 3 & 0.074 & 0.182 & 0.84 & -0.034 & 0.073 \\
\hline
\end{tabular}

Extraction Method: Principal Component Analysis.

Rotation Method: Varimax with Kaiser Normalization.

a. Rotation converged in 7 iterations.

Figure 1. Proposed Conceptual Model to Assess Productivity (MAP) of University Members.

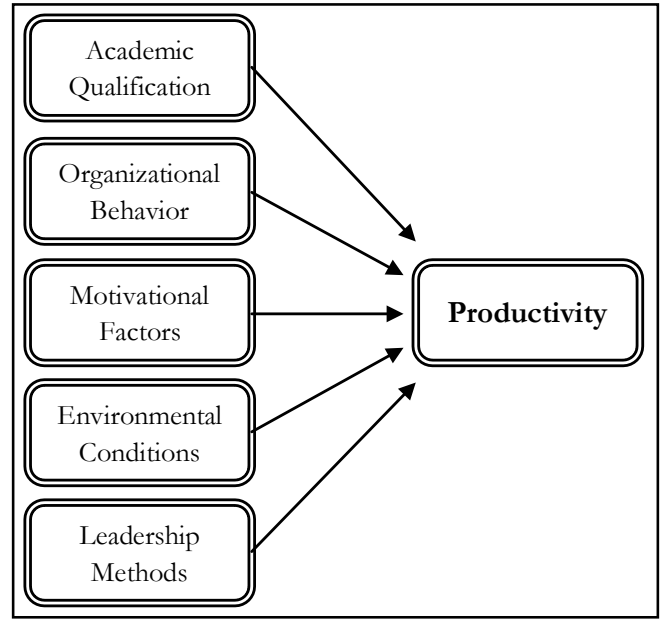

techniques, (2) choosing factor extraction methods such as principal components analysis, principal axis factoring, image factoring, maximum likelihood, alpha factoring, unweighted least squares, generalized least squares and canonical, (3) selecting factor retention methods using; cumulative percentage of variance, K1 - Kaiser's, scree Test, minimum average partial approaches and parallel analysis, (4) selection of rotational method, whether orthogonal rotations or Oblique rotation and finally, (5) interpretation and labeling of factors.

\section{References}

[1]. Barr RB, Tagg J. From teaching to learning a new paradigm for undergraduate education. Change: The Magazine of Higher Learning, 1995; 27(6): 1325.

[2]. Taherdoost H, Madanchian M. Empirical Modeling of Customer Satisfaction for E-Services in Cross-Border E-Commerce. Electronics. 2021 Jan;10(13):1547.

[3]. Taherdoost H. Exploratory Factor Analysis; Concepts and Theory. Advances in Applied and Pure Mathematics, 2014: 375-382.

[4]. Taherdoost H. Evaluation of Customer Satisfaction in the Digital Environment: Development of a Survey Instrument. InDigital Transformation and 
Innovative Services for Business and Learning, IGI Global. 2020: 195-222.

[5]. Taherdoost H. Handbook on Research Skills: The Essential Step-By-Step Guide on How to Do a Research Project. 2021: Amazon Kindle.

[6]. Taherdoost, H., Determining Sample Size; How to Calculate Survey Sample Size. International Journal of Economics and Management Systems, 2017: (2) $237-239$.

[7]. Taherdoost H. Sampling Methods in Research Methodology; How to Choose a Sampling Technique for Research. International Journal of Academic Research in Management, 2016; 5(2): 18-27.

[8]. Weiss D. The relationship between faculty group development \& faculty productivity in higher education. Temple University. 1998.

[9]. Doellefeld S. Faculty Productivity: A Conceptual Analysis \& Research Synthesis. State University of New York: NY, U.S.A. 1998.

[10]. Morris I, R M. Effective organizational culture is key to a company's longterm success. Industrial Management, 1992; 34(2): 28.

[11]. Chang LC, Liu CH. Employee empowerment, innovative behavior and job productivity of public health nurses: A cross-sectional questionnaire survey. International journal of nursing studies. 2008 Oct 1;45(10):1442-8.

[12]. Scott P. Higher education reformed, London: Falmer press, 2000.

[13]. Loke C. Leadership behaviors: effect on job satisfaction, productivity and organizational commitment. Journal Nursing Management, 2001; 9(4): 191-204.

[14]. Sulo T, Kendagor R, Kosgei D, Tuitoek D, Chelangat S. Factors affecting research productivity in public universities of Kenya: the case of Moi University, Eldoret. Journal of Emerging Trends in Economics and Management Sciences. 2012 Oct 1;3(5):475-84.

[15]. Taherdoost $\mathrm{H}$. How to design and create an effective survey/questionnaire; A step by step guide. International Journal of Academic Research in Management (IJARM). 2016 Aug 1;5(4):37-41.

[16]. George D, P Mallery. SPSS for Windows step by step: A simple guide and reference. 4th ed ed. 2003: Boston: Allyn \& Bacon.
[17]. Hair JF. Multivariate Data Analysis. fifth ed ed. 1998, Englewood Cliffs, NJ.: Prentice Hall.

[18]. Nunnally J. Psychometric Theory. Second Edition ed. 1978, New York: NY: McGraw-Hill.

[19]. Whitley BE. Principals of Research and Behavioural Science. 2002, Boston: McGraw-Hill.

[20]. Robinson J. Triandis theory of interpersonal behaviour in understanding software privace behaviour in the South African context, in School of Human \& Community Development, University of the Witwatersrand: Johannesburg. 2009: 108.

[21]. Leech N, K Barrett, G Morgan A. SPSS for intermediate statistics: Use and interpretation. 2nd ed. London: Lawrence Erlbaum Associates. 2005.

[22]. Taherdoost H. Validity and Reliability of the Research Instrument; How to Test the Validation of a Questionnaire/Survey in a Research. International Journal of Academic Research in Management, 2016; 5(3): 28-36.

[23]. Netemeyer RG, Bearden WO, Sharma S. Scaling procedures: Issues and applications. Sage Publications; 2003 Mar 12.

[24]. Kaiser HF. The application of electronic computers to factor analysis. Educational and psychological measurement. 1960 Apr;20(1):141-51.

[25]. Fabrigar LR, Wegener DT, MacCallum RC, Strahan EJ. Evaluating the use of exploratory factor analysis in psychological research. Psychological methods. 1999 Sep;4(3):272.

[26]. Gorsuch R. Factor Analysis. 1983: Hillsdale, NJ: Erlbaum.

[27]. Taherdoost H. Electronic service quality measurement: development of a survey instrument to measure the quality of e-service. International Journal of Intelligent Engineering Informatics. 2019;7(6):491-528. 